\title{
Wheezing in infants: frequency, clinical characteristics and treatment
}

\author{
Maiara Lanna Bouzas, ${ }^{1}$ Dirceu Solé, ${ }^{2}$ Maria Regina A. Cardoso, ${ }^{3}$ Eliana E. V. Silva, ${ }^{4}$ \\ Karen S. Miranda, ${ }^{4}$ Laíse R. Néri, ${ }^{4}$ Patrícia F. C. Silva, ${ }^{4}$ Ramon S. Amoedo, ${ }^{5}$ \\ Rômulo B. Meneses, ${ }^{4}$ Aldina Barral, ${ }^{6}$ Cristiana M. Nascimento-Carvalho7
}

\begin{abstract}
Objective: To estimate the frequency and describe the clinical characteristics and respective treatments of previous history of wheezing.

Methods: Infants aged 6-23 months with upper respiratory tract complaints and reporting previous wheezing were followed-up retrospectively. Data were registered on a validated standardized form.

Results: Out of 451 infants, 164 (36.4\%; 95\%CI: 31.9-41.0) had a report of prior history of wheezing, $148(32.8 \% ; 95 \%$ CI: 28.5-37.4) during the first year of life. The mean age at the first episode of wheezing was $5.3 \pm 3.9$ months. Among those who had had their first episode before 12 months of age, $38.5 \%$ reported 3 to 6 episodes and $14.2 \%>6$ episodes. Mean age at first episode was lower for those with $\geq 3$ episodes in comparison with those with $\leq 2$ episodes $(3.2 \pm 2.7$ vs. $5.7 \pm 2.5$ months, $p<0.001)$.

Conclusion: One third of the infants reported wheezing during the first year of life. The earlier the first episode occurs, the more frequently wheezing recurs.
\end{abstract}

J Pediatr (Rio J). 2012;88(4):361-5: Asthma, wheezing, wheezy baby syndrome, wheezy infant syndrome.

\section{Introduction}

Recurrent wheezing in infants and early diagnosis of asthma have been a challenge for the medical community for some time now. An international study employing a validated, standardized instrument found differences between several different regions in Latin America and Europe in terms of prevalence, severity and several other characteristics of childhood wheezing episodes. ${ }^{1}$

According to the Brazilian Ministry of Health, respiratory diseases are responsible for $35.7 \%$ of all hospitalizations of children under 1 year old in the state of Bahia, and wheezing is one of the symptoms that causes parents and guardians the greatest anxiety. ${ }^{2}$ Generally, the first episode of wheezing occurs during the first year of life and is associated with upper airway respiratory infection (UARI), and this is especially true of recurrent forms. ${ }^{3}$

Many common respiratory viruses can trigger recurrent wheezing, which in turn can have an impact later in childhood. ${ }^{4}$ The most often identified viruses in the first

1. Physical therapist. Master's candidate of Programa de Pós-Graduação em Ciências da Saúde, Faculdade de Medicina da Bahia, Universidade Federal da Bahia (UFBA), Salvador, BA, Brazil.

2. Full tenured professor, Disciplina de Alergia, Imunologia Clínica e Reumatologia, Departamento de Pediatria, Escola Paulista de Medicina, Universidade Federal de São Paulo, (UNIFESP-EPM), São Paulo, SP, Brazil.

3. Associate tenured professor, Departamento de Epidemiologia, Faculdade de Saúde Pública, Universidade de São Paulo (USP), São Paulo, SP, Brazil.

4. Medical student, Escola Bahiana de Medicina e Saúde Pública (EBMSP), Salvador, BA, Brazil.

5. Medical student, UFBA, Salvador, BA, Brazil.

6. PhD. Adjunct professor, Departamento de Anatomia Patológica e Medicina Legal, Faculdade de Medicina da Bahia, UFBA, Salvador, BA, Brazil.

7. Associate tenured professor, Departamento de Pediatria, Faculdade de Medicina da Bahia, UFBA, Salvador, BA, Brazil.

No conflicts of interest declared concerning the publication of this article.

Financial support: Fundação de Amparo à Pesquisa do Estado da Bahia (FAPESB) and Conselho Nacional de Desenvolvimento Científico e Tecnológico (CNPq).

Suggested citation: Bouzas ML, Solé D, Cardoso MR, Silva EE, Miranda KS, Néri LR, et al. Wheezing in infants: frequency, clinical characteristics and treatment. J Pediatr (Rio J). 2012;88(4):361-5.

Manuscript submitted Nov 28 2011, accepted for publication Jan 272012.

http://dx.doi.org/10.2223/JPED.2187 
episode of wheezing in infants are respiratory syncytial virus and rhinovirus and, less often, parainfluenza, metapneumovirus, coronavirus, influenza, bocavirus and adenovirus have also been identified in this context. ${ }^{5}$ To date, the characteristics of recurrent wheezing among infants in the city of Salvador, BA, Brazil, are unknown.

The objectives of this study were to estimate the frequency of previous history of wheezing episodes in infants ( 6 to 23 months old) and describe their clinical characteristics and the forms of treatment used during these episodes.

\section{Patients and methods}

Between September 2009 and June 2011, children aged 6 to 23 months, brought for treatment to the walkin center at the Centro Pediátrico Professor Hosannah de Oliveira (open weekdays from 7 a.m. to 7 p.m.), at the Universidade Federal da Bahia (UFBA), in the city of Salvador, BA, were selected for this retrospective cohort. Children who presented between 8 a.m. and 5 p.m. with a history of UARI characterized by fever, coughing, sneezing, coryza or nasal obstruction lasting less than 7 days and with a report of previous wheezing were included. After providing consent, the International Study on the Prevalence of Wheezing in Infants (Estudio Internacional de Sibilancias en Lactantes, EISL) questionnaire ${ }^{6}$ was administered to parents or guardians of the children recruited. This questionnaire has been validated for the Brazilian culture. The questionnaire was administered by the research leader (M.L.B.) and six undergraduate students of medicine.

The following definitions were adopted: occasional wheezing (up to two episodes), recurrent wheezing (three or more episodes), severe recurrent wheezing (more than six episodes) ${ }^{7}$ and severe wheezing (emergency visit or hospital admission, or frequent waking at night, or difficulties breathing during a wheezing episode). ${ }^{8}$ The database was input to Epi-Info 6.04 and analyses were conducted using SPSS 9.0. The frequencies of study variables were extracted, with their respective 95\% confidence intervals ( $95 \% \mathrm{CI})$; Student's $t$ test was used for comparisons between variables with normal distribution, and differences between means and respective $95 \%$ CIs were calculated. The study was approved by the Research Ethics Committee at the UFBA's Maternidade Climério de Oliveira (protocol number 067/2009).

\section{Results}

Of a total of 451 children assessed, 164 (36.4\%; $95 \% \mathrm{CI}=$ $31.9-41.0)$ had a previous history of wheezing and 148 $(32.8 \% ; 95 \% \mathrm{CI}=28.5-37.4)$ had a history of wheezing in the first year of life.

The mean age of children with previous wheezing was $15 \pm 5$ months (range $=6$ to 23.9 months), and $62(37.8 \%)$ of them were less than 1 year old. There were 98 boys $(59.8 \%)$. The mean age of the children at the first episode of wheezing was $5.3 \pm 3.9$ months (median $=5$ months) and in $58.5 \%$ the first episode occurred before 6 months and in the first year of life in $90.2 \%$ (Table 1). Age at first episode of wheezing was $4.4 \pm 2.9$ months for children who had first symptoms during the first year of life and was $3.2 \pm 2.7$ months for those who also had recurrent wheezing. Recurrent wheezing affected $52.7 \%$ of infants who had their first symptoms during their first year of life, and was severe in $14.2 \%$ of these cases. With respect to the study group as a whole, the most often employed treatments during wheezing episodes were bronchodilators (89.6\%) and oral corticoids $(46.3 \%)$ (Table 2 ).

Table 1 - Distribution of children $(n=164)$ by age of first wheezing episode

\begin{tabular}{|c|c|c|c|}
\hline Age (months) & Frequency & Absolute \% & Cumulative \% \\
\hline $0-2$ & 48 & 29.3 & 29.3 \\
\hline $3-5$ & 48 & 29.3 & 58.5 \\
\hline $6-8$ & 40 & 24.4 & 82.9 \\
\hline $9-11$ & 12 & 7.3 & 90.2 \\
\hline $12-14$ & 12 & 7.3 & 97.6 \\
\hline $15-17$ & 3 & 1.8 & 99.4 \\
\hline $18-23$ & 1 & 0.6 & 100.0 \\
\hline
\end{tabular}


Infants with recurrent wheezing had symptoms earlier than occasional wheezers (3.2 \pm 2.7 months vs. $5.7 \pm 2.5$ months, $\mathrm{p}<0.001$; difference between means $=2.5$; $95 \% \mathrm{CI}=1.7-3.4)$. Irrespective of age at first episode of wheezing, the majority of cases involved a concomitant report of UARI (82.2\%). Table 2 shows the frequencies of different characteristics of wheezing episodes for the subset of infants who wheezed at least once during the first year of life and for the subset with recurrent wheezing during the first year of life. Severe wheezing was detected in 141 (86\%) infants and mean age for patients with severe wheezing was $5 \pm 4$ and for those without severe wheezing mean age was $7 \pm 4(p=0.04$; difference between means $=2$; $95 \% \mathrm{CI}=0.4-3.5)$.

\section{Discussion}

Of note is the early age at which the children studied presented their first episodes of wheezing, particularly those with recurrent cases (mean $=3.2$ months), which is a younger mean age than observed by studies undertaken in cities in the South and Southeast of Brazil, despite these having been undertaken at public services destined to underprivileged populations. ${ }^{9-11}$ A Dutch study documented a lower mean age of onset of wheezing (1.7 \pm 3.0 months) and observed a strong association between exposure to humidity at home and wheezing episodes. ${ }^{12}$ In contrast, a study of childhood asthma conducted in the city of Salvador found there was no association between atopic disease and the majority of cases of asthma in the population, ${ }^{3}$ suggesting that there was a stronger relationship between wheezing episodes and UARI and with lower airway respiratory diseases. ${ }^{13}$

We found that $32.8 \%$ of the entire sample had a first episode of wheezing during the first year of life, which is a similar result to what was observed by the EISL, i.e., the prevalence of wheezing in developing countries is higher than in developed ones.8,12,13 It is possible that local ecological and environmental factors may be responsible for these differences.

The prevalence of recurrent wheezing observed here $(52.7 \%)$ was lower than has been reported by other studies conducted in the Southeast and South regions of Brazil. 9,11

Table 2 - Clinical characteristics of patients (6-23 months) and forms of treatments utilized, by characteristics of wheezing episode occurrence

\begin{tabular}{|c|c|c|c|}
\hline Characteristics & $\begin{array}{c}\text { Total } \\
(\mathrm{n}=164)\end{array}$ & $\begin{array}{l}\text { Wheezing during } \\
\text { first year of life } \\
\quad(n=148) *\end{array}$ & $\begin{array}{l}\text { Recurrent wheezing } \\
\text { during first year of life } \\
(\mathbf{n}=\mathbf{7 8})\end{array}$ \\
\hline \multicolumn{4}{|l|}{ Clinical characteristics } \\
\hline Prior wheezing & $164(100 \%)$ & $148(100 \%)$ & $78(100 \%)$ \\
\hline Wheezing during first year of life & $148(90.2 \%)$ & $148(100 \%)$ & $78(100 \%)$ \\
\hline Emergency visit & $118(72 \%)$ & $107(72.3 \%)$ & $58(74.4 \%)$ \\
\hline Breathing difficulties & $94(57.3 \%)$ & $85(57.4 \%)$ & $51(65.4 \%)$ \\
\hline Hospital admissions & $60(36.6 \%)$ & $59(39.9 \%)$ & $42(53.8 \%)$ \\
\hline Physician-diagnosed asthma & $4(2.4 \%)$ & $4(2.7 \%)$ & $4(5.1 \%)$ \\
\hline \multicolumn{4}{|l|}{ Wakes at night because of wheezing } \\
\hline Never & $27(16.5 \%)$ & $23(15.5 \%)$ & $7(9.0 \%)$ \\
\hline Rarely & $78(47.6 \%)$ & $68(45.9 \%)$ & $31(39.7 \%)$ \\
\hline Sometimes & $39(23.8 \%)$ & $37(25.0 \%)$ & $26(33.3 \%)$ \\
\hline Frequently & $20(12.2 \%)$ & $20(13.5 \%)$ & $14(17.9 \%)$ \\
\hline \multicolumn{4}{|l|}{ Types of treatment } \\
\hline Bronchodilators & $147(89.6 \%)$ & $134(90.5 \%)$ & $74(94.9 \%)$ \\
\hline Oral corticosteroids & $76(46.3 \%)$ & $72(48.6 \%)$ & $46(59.0 \%)$ \\
\hline Inhaled corticosteroids & $20(12.2 \%)$ & $19(12.8 \%)$ & $9(11.5 \%)$ \\
\hline Antileukotrienes & $2(1.2 \%)$ & $2(1.4 \%)$ & $1(1.3 \%)$ \\
\hline
\end{tabular}

* One or more episodes.

† Three or more episodes. 
The same was true of the prevalence of severe recurrent wheezing. ${ }^{9}$ The explanation for these differences is highly complex and involves multiple factors. One suggestion is that genetic and environmental interactions are distinct in every location and are capable of modulating airway responses from very early in life up to adulthood. ${ }^{8}$

In this study, there was an elevated rate of concomitance between wheezing episodes and UARI ( $82.2 \%)$, in line with other studies that have suggested that $85 \%$ of wheezing episodes in infants have viral etiology. ${ }^{4}$ Many different hypotheses have been raised to attempt to explain this relationship. The first suggestion is that viral infections may affect development of the immunoresponse or interfere with normal pulmonary development and with regulation of respiratory tract tonus. The second suggestion is that the virus could cause obstruction of the respiratory tract in people who already have disorders of airway primary function or structure or a susceptibility to immunoresponses that predispose to obstruction. The final suggestion is that the response to different viruses depends on genetic history, on exposure to other environmental factors and on the degree of maturity of the respiratory and immunological systems. ${ }^{14}$

Treatment of acute wheezing is with inhaled beta-2 agonist bronchodilators and oral corticosteroids for a limited period of time. ${ }^{15}$ Therefore, the high frequency of administration of these medications in our sample of infants does not surprise us ( $89.6 \%$ were given bronchodilators and $46.3 \%$ oral corticosteroids). 8,9 Beta-2 agonists offer rapid relief from symptoms, particularly bronchial obstruction. ${ }^{16}$ The effect expected from the corticosteroids, via their potent anti-inflammatory properties, is repair of sequelae of the viral infection. However, several different studies using high and low doses of inhaled or systemic corticosteroids have reported conflicting results, since the majority were unable to demonstrate significant reductions in symptoms, length of hospital stay or need for mechanical ventilation. ${ }^{17}$ In contrast, a very small proportion of patients were given leukotriene receptor antagonists to manage their wheezing, as has been reported in other studies. ${ }^{8}$ The fact that this group of drugs is not dispensed by primary care providers, allied to their high cost, may explain this fact.

The earlier the first episode occurred, the more frequently severe wheezing was reported, although physiciandiagnosed asthma was rare (Table 2), in common with what has been observed in other cities in the Northeast region of Brazil. 8

Our study suffers from certain limitations: surveillance and recruitment were not undertaken during the last 2 hours of each working day, although the service was still open, which may have led to losses. Approximately one third of the children recruited had not yet reached 12 months of age, which could have led to underestimation of frequencies. Nevertheless, the sample recruitment team were trained intensively and its members were medical students, which, in conjunction with the adequate level of understanding and well-preserved memory on the part of the mothers interviewed (which has been demonstrated previously), 6,9 indicates that the results should be trustworthy.

We conclude that wheezing is a sign with early onset and elevated prevalence in the city of Salvador, although prevalence is lower than has been reported by studies undertaken in other Brazilian cities. A significant percentage of these patients are treated with systemic corticosteroids, possibly justified by the severity of the episodes.

\section{References}

1. Mallol J, García-Marques L. Estudio Internacional de Sibilancias en Lactantes (EISL) [Internet]. 2006. http://www.respirar.org/ pdf/eisl/eisl_visiondeconjunto.pdf. Access: 14/10/2011.

2. Brasil. Ministério da Saúde. Proporção de internações hospitalares (SUS) por grupos de causas. DATASUS [Internet]. http:// tabnet.datasus.gov.br/cgi/tabcgi.exe?idb2009/d13.def. Access: 14/10/2011.

3. Souza da Cunha S, Barreto ML, Fiaccone RL, Cooper PJ, AlcantaraNeves NM, Simões $S$ de $M$, et al. Asthma cases in childhood attributed to atopy in tropical area in Brazil. Rev Panam Salud Publica. 2010;28:405-11.

4. Jartti T, Lee WM, Pappas T, Evans M, Lemanske RF Jr, Gern JE. Serial viral infections in infants with recurrent respiratory illnesses. Eur Respir J. 2008;32:314-20.

5. Jackson DJ, Lemanske RF Jr. The role of respiratory virus infections in childhood asthma inception. Immunol Allergy Clin North Am. 2010;30:513-22.

6. Chong Neto HJ, Rosário NA. Expanding the application of a standardized questionnaire on recurrent wheezing in infancy. J Pediatr (Rio J). 2009;85:170-4.

7. Chong Neto $\mathrm{HJ}$, Rosário NA. Wheezing in infancy: epidemiology, investigation, and treatment. J Pediatr (Rio J). 2010;86:171-8.

8. Mallol J, García-Marcos L, Solé D, Brand P; EISL Study Group. International prevalence of recurrent wheezing during the first year of life: variability, treatment patterns and use of health resources. Thorax. 2010;65:1004-9.

9. Dela Bianca AC, Wandalsen GF, Mallol J, Solé D. Prevalence and severity of wheezing in the first year of life. J Bras Pneumol. 2010;36:402-9

10. Lima JA, Fischer GB, Sarria EE, Mattiello R, Solé D. Prevalence of and risk factors for wheezing in the first year of life. J Bras Pneumol. 2010;36:525-31.

11. Chong Neto HJ, Rosário NA, Grasselli EA, e Silva FC, Bojarski L de F, Rosário CS, et al. Recurrent wheezing in infants: epidemiological changes. J Pediatr (Rio J). 2011;87:547-50.

12. Visser CA, Garcia-Marcos L, Eggink J, Brand PL. Prevalence and risk factors of wheeze in Dutch infants in their first year of life. Pediatr Pulmonol. 2010;45:149-56.

13. Garcia-Marcos L, Mallol J, Solé D, Brand PL; EISL Study Group. International study of wheezing in infants: risk factors in affluent and non-affluent countries during the first year of life. Pediatr Allergy Immunol. 2010;21:878-88.

14. Martinez FD. The connection between early life wheezing and subsequent asthma: The viral march. Allergol Immunopathol (Madr). 2009;37:249-51.

15. GINA Report. Global Strategy for Asthma Management and Prevention. Updated December 2010. Evidence-based guidelines for asthma management and prevention, with citations from the scientific literature [Internet]. http://www.ginasthma.org. Access: 14/10/2011. 
16. Jartti $\mathrm{T}$, Lehtinen $\mathrm{P}$, Vanto $\mathrm{T}$, Vuorinen $\mathrm{T}$, Hartiala J, Hiekkanen $\mathrm{H}$, et al. Efficacy of prednisolone in children hospitalized for recurrent wheezing. Pediatr Allergy Immunol. 2007;18:326-34.

17. Tregoning JS, Schwarze J. Respiratory viral infections in infants: causes, clinical symptoms, virology, and immunology. Clin Microbiol Rev. 2010;23:74-98.
Correspondence:

Maiara Lanna Bouzas

Programa de Pós-Graduação em Ciências da Saúde, Faculdade de Medicina da Bahia, Universidade Federal da Bahia

Largo do Terreiro de Jesus, $\mathrm{s} / \mathrm{n}$

CEP 40025-010 - Centro Histórico, Salvador, BA - Brazil

Tel.: +55 (71) 8895.2221

E-mail: maiara.lanna@gmail.com 